\title{
Interpretação fenomenológica do conceito de "solicitude" no pensamento pedagógico de La Salle
}

\author{
Phenomenological interpretation of the concept of "solicitude" in the \\ pedagogical thought of La Salle
}

\author{
CLEITON LUIZ KERBER ${ }^{1}$
}

\begin{abstract}
Resumo: A preocupação é comportamento derivado do existencial cuidado que, segundo Heidegger, é "a essência da existência humana". Pensada como tal, a preocupação (Fürsorge) pode ser associada à solicitude (solicitude) na base prática e teórica dos escritos pedagógicos de João Batista de La Salle, educador cristão do século XVII e patrono da educação universal. O que se pretende apresentar nesta pesquisa teórica e de cunho bibliográfico é determinar o sentido de solicitude no pensamento pedagógico de La Salle por meio de uma interpretação fenomenológica. Aborda-se a compreensão das premissas orientadoras do pensamento pedagógico lassaliano e como o papel do educador assume uma função não somente de um profissional da educação, mas sim como alguém que deixa guiar a sua conduta como pedagogo pelo viés da solicitude. Busca-se analisar a aproximação entre o conceito de solicitude de La Salle e a ideia de preocupação na fenomenologia existencial de Heidegger. Os dois pensadores partem de pressupostos compatíveis: Heidegger pensa o cuidado e a preocupação na chave de uma co-existência (Mit-sein) e La Salle trata o cuidado como a solicitude perante seus educandos como modo de orientá-los. Neste sentido, a solicitude seria possível de ser apropriada pela filosofia existencial heideggeriana ao falarmos de preocupação; porém, La Salle, em suas teorias pedagógicas, ainda retém certo componente humanista, traço de sua orientação cristã, o que não se observa na filosofia heideggeriana.
\end{abstract}

Palavras-chave: La Salle. Heidegger. Fenomenologia existencial. Pedagogia da solicitude.

Abstract: Worry is behavior derived from existential care which, according to Heidegger, is "the essence of human existence." Considered as such, concern (Fürsorge) can be associated with concern (solicitude) in the practical and theoretical basis of the pedagogical writings of John Baptist de La Salle, a Christian educator of the seventeenth century and patron of universal education. The purpose of this theoretical and bibliographical research is to determine the sense of solicitude in La Salle's pedagogical thinking through a phenomenological interpretation. It addresses the understanding of the guiding premises of Lasallian pedagogical thinking and how the role of the educator assumes a role not only of a professional education but as one who guides his behavior as a pedagogue for the bias of solicitude. It is sought to analyze the approach between the concept of solicitude of La Salle and the idea of concern in Heidegger's existential phenomenology. The two thinkers start from compatible presuppositions: Heidegger thinks of care and concern in the key of coexistence (Mit-sein) and La Salle treats care as solicitude towards his students as a way of guiding them. In this sense, solicitude would be possible to be appropriated by the Heideggerian existential philosophy in speaking of concern; but La Salle, in his pedagogical theories, still retains a certain humanist component, a trace of his Christian orientation, which is not observed in Heidegger's philosophy.

Keywords: La Salle. Heidegger. Existential Phenomenology. Pedagogy of solicitude.

\footnotetext{
${ }^{1}$ E-mail: cleiton.kerber@lasalle.org.br
} 


\section{Introdução}

O conceito de solicitude apresentado nos escritos pedagógicos de João Batista de La Salle, caracteriza-se e ganha aproximação ao conceito de preocupação (fürsorge) presente na filosofia existencialista de Heidegger. La Salle busca apresentar uma pedagogia onde a relação entre o educador e o educando é caracterizada pela forma de preocupação, gerando assim uma pedagogia da solicitude.

O presente trabalho visa analisar essa possível relação entre o conceito de solicitude, presente na pedagogia de La Salle, a luz da fenomenologia existencial do filosofo alemão Martin Heidegger. Busca-se trazer à tona a forma como são apresentados pelos dois autores os seus conceitos, visando apresentar como a preocupação em Heidegger é caracterizada em La Salle como solicitude.

Inicialmente, examina-se nos escritos de La Salle como se dá relação entre o professor e o aluno, buscando perceber as formas em que se gera o processo de preocupação e como ele se caracteriza como solicitude. Em seguida, busca-se analisar através da filosofia de Heidegger, em especial na obra Ser e Tempo, como o conceito de preocupação é apresentado, e como ele ganha proximidade, pelo viés do existencialismo, ao conceito de solicitude apresentado por La Salle.

\section{Notas da vida e obra de João Batista de La Salle}

Sacerdote e educador francês, João Batista de La Salle (1651-1719) foi fundador de uma congregação religiosa masculina atuante em meio a educação, a “Congregação dos Irmãos das Escolas Cristãs”. La Salle viveu na França, a partir da metade do século XVII, período em que a sociedade francesa era assolada pela fome, doenças, banditismo e miséria, principalmente a população mais carente.

De origem nobre, La Salle, diferente da grande maioria da população francesa, recebeu boa educação, graduando-se em teologia e filosofia, e após adquire o título de Doutor em teologia. Ao perceber a realidade de miséria que afligia a população mais carente de sua época, começa a fundar escolas em regiões de difícil acesso à educação, principalmente em bairros pobres e de periferias de grandes cidades, como Reims, Ruão e Paris, recebendo o apoio de pessoas conhecidas, os quais garantiam os fundos para a manutenção das escolas, sendo estes fundadores das escolas, pois garantiam os meios necessários para o seu custeio.

Fundadas algumas escolas, La Salle vê a necessidade de criar uma congregação religiosa de irmãos que se dediquem a evangelização e a educação das crianças e jovens pobres. Essa congregação formada por religiosos leigos, foi denominada de "Congregação dos Irmãos das Escolas Cristãs", que atuavam de forma direta em meio a educação. Além de fundar as escolas e a congregação religiosa, La Salle produz diversas obras referentes à ação pedagógica, busca criar um material que 
sirva de apoio tanto ao mestre como ao aluno. Em 1695, escreve o livro Guia das Escolas Cristãs, obra que servia de base para a ação pedagógica dos professores. Em sua maioria, esses primeiros colaboradores da obra eram homens simples, que possuíam baixo grau de formação. Por isso, La Salle que

[...] era, por temperamento e educação, avesso às improvisações e à rotina. Espírito metódico e clarividente, traçou, para a direção de seus discípulos, um manual de orientação prática no difícil mister do ensino e da educação: o "Guia das Escolas Cristãs" (JUSTO, 1991, p. 97).

O Guia das Escolas Cristãs servia de base aos educadores, em especial aos Irmãos que atuavam em sala de aula, para que colocassem em prática métodos que fossem aplicados de forma universal em todas as escolas fundadas por La Salle e sua congregação religiosa. João Batista de La Salle buscou deixar isso claro aos seus educadores, por esse motivo afirma logo no prefácio da obra as intenções de redigir o Guia, ali se lê:

Foi preciso redigir este Guia das Escolas Cristãs, para que houvesse uniformidade em todas as escolas e localidades em que se encontram Irmãos deste Instituto e para que as práticas nelas fossem sempre idênticas. O homem é tão inclinado ao relaxamento, inclusive à mudança, que necessita regras escritas para retê-lo nos limites de seu dever e para impedir que introduza alguma novidade ou destrua o que foi sabiamente estabelecido (LA SALLE, 2012, p. 19a)

Em seguida, La Salle indica os métodos descritos no Guia das Escolas Cristãs. Com este, buscou trazer à tona que o trabalho nele descrito não foi elaborado unicamente por ele ou somente de suas reflexões dadas por suas experiências como educador, mas sim através de sua forma comunitária de aplicabilidade de métodos pedagógicos e de reflexão em conjunto com outros Irmãos educadores que buscaram com La Salle apresentar os procedimentos a serrem utilizados nas Escolas dos Irmãos. Assim:

Este guia não foi redigido em forma de regulamento após numerosas trocas de ideias entre os Irmãos mais antigos deste Instituto e os mais aptos em dar aula, e após experiência de vários anos. Nada foi nele introduzido que não fosse muito consensual e bem comprovado, de que não se estivessem ponderado as vantagens e inconvenientes e previsto, tanto quanto possível, as boas ou más consequências (LA SALLE, 2012, p. 12a).

Além do Guia das Escolas Cristãs, La Salle redigiu também diversas meditações com o foco de dar aos Irmãos elementos que venham agregar na reflexão de suas práticas como um educador religioso cristão. Foram compostas três grupos de meditações por La Salle: Meditação para o tempo de retiro, também chamadas de 
Meditações sobre o emprego da escola; Meditações para todos os Domingos do Ano; e Meditações sobre as principais Festas do Ano. Foram escritas 207 meditações por João Batista de La Salle e cada meditação é dividida em três pontos, cada ponto apresenta uma ideia central que se termina com uma aplicação possível a quem a medita (LA SALLE, 2012, p. o9b).

\section{Linhas de força do pensamento pedagógico lassaliano}

Os escritos de João Batista de La Salle possuíam como intuito guiar os educadores para uma boa prática pedagógica. A educação das Escolas Cristãs, dada por La Salle e os primeiros Irmãos, era destinada as camadas mais populares, e visavam apresentar um ensino voltado para a vida das crianças e jovens. Muito mais do que pensar um conteúdo teórico, distante da realidade e do contexto social dos alunos, o planejamento do conteúdo visava uma emancipação social.

O ensino, além de ser um meio de contribuir com a salvação da alma, por intermédio do ensino catequético cristão dado nas escolas dos Irmãos, também deveria ser um meio de contribuir para a melhoria da vida dos alunos. La Salle, buscou implantar técnicas pedagógicas que viessem contribuir para as futuras funções que as crianças que frequentavam as suas escolas viessem exercer, que na maioria das vezes, seriam as exercidas por seus pais e familiares. Para isso, algumas práticas pedagógicas contemporâneas a La Salle, seriam tanto quanto inúteis para as crianças e jovens que frequentavam as Escolas dos Irmãos. Uma prática abolida por La Salle e os Irmãos em suas escolas foi o estudo do latim, pois é,

[...] praticamente, inútil às profissões manuais e do comércio. A duração dos estudos é demasiado breve para os pobres e obreiros poderem assimilar a cultura latina. Eis a razão por não constar esse idioma no programa, a não ser em segundo plano e como simples elemento de leitura. O conhecimento do francês figura em primeiro lugar. É espécie de revolução nos hábitos estabelecidos (POUTET; PONGIER, 2001, p. 118).

Buscou-se aplicar uma educação que se contribui com a vida dos estudantes, que viesse futuramente contribuir para as suas vidas e para o exercício do trabalho que iriam exercer. Os conteúdos não surgiam de uma forma contraria a realidade dos e discentes, mas "brotados do interior do meio escolar e não impostos por autoridade, são antes de tudo, adequados as necessidades do povo" (POUTET; PONGIER, 2001, p. 118). Como em sua maioria, os alunos atendidos pelas escolas fundadas por La Salle, e os primeiros Irmãos eram de origem pobre e humilde, prezava-se pela gratuidade do ensino, referente a uma escola pública, que fosse acessível a todos.

Além da gratuidade das Escolas Cristãs, que gerou uma educação inclusiva, acessível a todas as camadas sociais, La Salle assume outros princípios que visam dar 
uma qualidade didática e pedagógica a sua educação: a persuasão, escola e professores atrativos, ensino eficaz e adequado, método de ensino de massas e "endomarketing".

O princípio da persuasão pretende dar ênfase no incentivo da frequência dos alunos nas aulas, mas que não seja uma presença no sentido de obrigatoriedade, mas que se sintam bem em frequentar o ambiente escolar e o "desejem fazê-lo e pelo tempo necessário à sua escolarização. Por isso, La Salle recomendava que fossem observadas as causas das ausências e os modos de evitá-las" (RANGEL; WESCHENFELDER, 2010, p. 13).

La Salle queria que a escola e os professores fossem atrativos para os alunos, para isso, em seu Guia das Escolas Cristãs chega a afirmar em relação aos educadores que: "É necessário proceder de maneira que os alunos saiam sempre satisfeitos da escola" (La Salle, 2012, p. 305a). Os professores, devem saber exercer bem o seu papel em aula, cuja a sua função na dinâmica de ensino e aprendizagem, juntamente com o seu papel de educador, demonstrem aos alunos um equilíbrio entre serem firmes e ternos, demonstrando assim sua autoridade e competência. Com relação à escola, La Salle mostra que ela deve ser sempre organizada e eficiente, e para isso necessita de bons professores, que tenham competência docente como mestres e sejam atrativos (RANGEL; WESCHENFELDER, 2010, p. 14).

O princípio de ensino eficaz e adequado requer muito esforço do professor segundo La Salle, pois o mestre deve ser "[...] competente e atrativos que, apesar do desinteresse da família pela escola, marcante na pobreza dos anos 1600 no contexto da França de La Salle, atraísse os alunos e os mantivessem na escola" (RANGEL; WESCHENFELDER, 2010, p. 14). O ensino também deve ser adequado ao interesse da realidade na qual está inserido o aluno, e que aprendam o que lhes sejam úteis para a sua vivência em sociedade, para a sua fé e para a sua futura profissão.

La Salle buscou aplicar também em suas escolas o princípio do método de ensino de massas, que visa o ensino simultâneo de atender e acolher um grande número de alunos. Na mesma sala, o professor atendia simultaneamente os alunos de forma individual e coletiva, buscando olhar cada aluno de forma singular, e percebendo a diferença em seus níveis e estágios de aprendizagem. Cabe ao mestre buscar manter ocupados todos os alunos, alguns acompanhando a leitura feita em voz alta por um aluno, e outros buscando resolver problemas de cálculo e realizando atividades de escrita. Nesse caso,

[...] é interessante perceber que, com a diversidade de métodos e exercícios, atendendo à diversidade de níveis de aprendizagem, o professor mantém os alunos em atividade, evitando que fiquem ociosos na aula e auxiliando-os a aproveitarem o tempo para a aprendizagem. Evita-se, também, assim, o desinteresse e a indisciplina, até porque, o aluno ocioso pode tornar-se 
potencialmente indisciplinado (RANGEL; WESCHENFELDER, 2010, p. 15).

Como último, mas não menos importante, La Salle destaca o princípio do "endomarketing". Seria este, uma forma de propaganda não paga das Escolas Cristãs. Esse método de divulgação seria feito pelas vozes daqueles que são atendidos pela instituição de ensino, ou seja, os próprios alunos. Por esse motivo, os demais princípios, principalmente os de eficiência e eficácia da escola, devem estar funcionando bem, para que se transformem em satisfação de alunos e famílias. São as próprias vozes saídas de dentro da escola que vão divulgar e assim trazer para a instituição novos alunos, buscando assim promover o progresso social do ensino (RANGEL; WESCHENFELDER, 2010, p. 16).

Percebesse, através desses princípios, a preocupação de La Salle e os primeiros Irmãos em levar um ensino de qualidade as crianças e famílias pobres da França do século XVII. A dimensão pedagógica das Escolas Cristãs atinge muitos através de seus métodos de ensino/aprendizagem, não somente no nível quantitativo, mas também de inclusão, tendo em vista que muitos que frequentavam as escolas de La Salle eram crianças predominantemente pobres e muitos até moradores de rua, onde em outras instituições de ensino seriam barrados por motivos físicos, de higiene ou por não saberem se comportam de forma sociável. La Salle percebe a realidade desses pequeninos e busca incorporar em suas escolas os métodos de ensino abordados acima, que visam dar aos seus alunos dignidade e buscar a sua salvação, não somente no contexto cristão, mas também de dar capacidade para que possam através de um ensino de qualidade melhorar as condições em que essas crianças se encontravam.

\section{O conceito de solicitude em La Salle}

A forma de educar apresentada por La Salle e os primeiros Irmãos mostra uma forma diferente da educação francesa do século XVII. Os mestres calígrafos, professores que recebiam pago para educar, visavam somente ensinar as crianças métodos que lhes seriam úteis para a vida pública, não estavam preocupados se realmente o ensino em que apresentavam era de qualidade e eficiente para aqueles aos quais prestavam o serviço.

La Salle tinham em mente que a educação prestada em suas escolas deveria ser de qualidade, útil a vida social da criança e que lhe ensinasse questões morais e sociais. Para isso, não bastava somente que o próprio estudante se preocupa com a sua educação, e que o educador visse o seu trabalho não somente no âmbito do serviço, mas sim como uma missão a ele confiada. Sendo La Salle um padre católico e fundador de uma Congregação Religiosa do Século XVII, essa missão, acreditava ele, baseada em sua fé, lhes era confiada por Deus. Baseando-se em seus princípios cristãos, escreve aos mestres: 
Não somente Deus quer que todos os homens cheguem ao conhecimento da verdade; quer também que todos sejam salvos. Porém, não pode querer isso de verdade, sem lhes dar os meios para tal, sem fornecer, portanto, às crianças os mestres que contribuam para a realização, nelas, desse desígnio (LA SALLE, 2012, p. 436b).

A educação das crianças, deveria ser segundo La Salle, de qualidade e que se fornece os elementos suficientes para lhes dar dignidade e garantir-lhes a sua salvação, para isso, o educador deve zelar e cuidar da educação de seus alunos, mas esse cuidado está no âmbito da preocupação. O docente, sendo assim, deve estar preocupado com a educação que seus discentes vão receber, mas essa preocupação assume a esfera da solicitude. A solicitude entendida por La Salle, contextualizandoa no meio da educação de seu tempo, assume a forma da preocupação que o educador deve ter pela educação e salvação de seus alunos, assumindo o professor a preocupação como forma de solicitude. Ao justificar sobre os motivos dessa preocupação, afirma aos mestres a necessidade,

[...] que vosso primeiro cuidado e o primeiro efeito de vossa vigilância no emprego seja estar sempre atentos aos vossos alunos, a fim de impedi-los de praticarem qualquer ação, não somente má, mas nem sequer um pouco inconveniente, levando-os a se absterem de tudo o que tenha a menor aparência de pecado (LA SALLE, 2012, p. $436 b)$.

Os professores não devem estar somente preocupados com a educação formal de seus alunos, mas também devem estar vigilantes com o que se refere as suas questões sociais e morais. A forma de preocupação afirmada por La Salle acima, refere-se também a questões de práticas da vida dos estudantes, o educador deve zelar para que seus alunos não pratiquem coisas más ou inconvenientes a vida em sociedade. Deve buscar com que seus alunos não caiam em atos que venham a prejudicar a sua vida em sociedade e como cristãos.

La Salle buscando dar exemplos de como os educadores devem agir para com seus educandos, busca elementos da própria religião e espiritualidade cristã, mostrando que os professores devem ser verdadeiros anjos da guarda de seus alunos: "Os anjos ensinam-lhes o bem que lhes convém praticar, mediante as luzes que comunicam aos homens [...]" (LA SALLE, 2012, p. 449b). Os anjos possuem o dever de comunicar as verdades divinas aos homens, o mesmo, aponta La Salle aos mestres de suas escolas, "[...] deveis fazer com relação as crianças confiadas a vossa solicitude" (LA SALLE, 2012, p. 449b), buscando assim comunicar aos seus estudantes as verdades que lhes devem ser ensinadas, para que tenham digna condição de se salvarem, tanto no âmbito religioso, como social. A figura dos anjos é utilizada por La Salle para caracterizar a solicitude que o professor deve ter perante seus alunos, assim como os anjos ensinam e comunicam as boas ações, também o educador deve comunicar a seus estudantes tanto as verdades da religião como da 
sociedade para que possam praticar o bem.

A solicitude do educador é entendida por La Salle como sendo o próprio ato do professor de preocupar-se com seus estudantes e com a educação que irão receber. O ato de educar, segundo La Salle, deve ser a maior das preocupações do professor, pois aqueles a quem foram confiadas as crianças, não o foram simplesmente para que os ensinassem as questões puramente teóricas. Os educandos lhes foram confiados a própria solicitude do professor, e afirma a eles que é,

[...] vosso dever, repreender os desregrados e empenhar-vos para que renunciem à vida passada, estimular os pusilânimes, suportar os fracos, ser pacientes com todos, a fim de poderdes refrear e conter tão eficazmente suas más inclinações e firmá-los de tal modo no bem [...] (LA SALLE, 2012, p. 45ob).

La Salle tenta mostrar que a profissão de professor ultrapassa os âmbitos simplesmente do trabalho remunerado, para isso lança as bases da forma como o educador deve buscar agir para com os seus estudantes, sendo ela através da preocupação, sendo este entendido como solicitude. $O$ professor não deve simplesmente ensinar, mas guiar aqueles aos quais lhe foram confiados, por esse motivo, não deve considerar-se como um profissional da educação, mas sim como "[...] embaixadores e ministros" (LA SALLE, 2012, p. 436b). O mestre, segundo La Salle, é aquele que acredita na sua ação como educador, e busca todos os meios necessários para exercê-lo, pois os alunos são tutelados pelo seu professor através da sua preocupação no ato de ensinar, ou seja, a ação de educar é indissociável da solicitude que o mestre possui sobre seus alunos.

\section{Do conceito de “preocupação" na filosofia existencial de Heidegger}

Além de La Salle, outros pensadores atentaram para a noção de solicitude, se não no campo da pedagogia, no terreno filosófico, no qual, antes mesmo de esta ser abordada sob o ponto de vista moral cristão, tratou-a no domínio da existência do humano. Entre esses, vemos o filósofo alemão Martin Heidegger (1889-1976) tratar do tema no seio de sua filosofia da existência, abordando não apenas a noção de preocupação, quanto conceitos a esta correlatos, como a "ocupação" e o "cuidado". ${ }^{2}$

\footnotetext{
2 A questão do cuidado se apresenta na filosofia existencial heideggeriana, onde o seu projeto busca refletir sobre o sentido do ser. Em Ser e Tempo, de 1927, Heidegger busca recolocar a pergunta sobre o ser, sua tentativa é recolocar na centralidade de sua reflexão filosófica a questão que animou a filosofia desde o tempo dos pré-socráticos, passando por Platão e Aristóteles, chegando até Hegel. Heidegger é o filosofo do ser, e suas considerações sobre o tema nos mostram o quanto de empenho buscou dar a essa questão, como nos aponta em sua obra: "Deve-se colocar a questão do sentido de ser. Tratando-se de uma ou até da questão fundamental, seu questionamento precisa, portanto, adquirir a devida transparência. Daí a necessidade de se discutir brevemente o que pertence a uma questão para, a partir daí poder-se mostrar a questão do ser como uma questão privilegiada" (HEIDEGGER, 2011, p. 40). A questão do ser é centro da filosofia existencial de Heidegger, e nesse âmbito que se desenvolve e é trabalhada a reflexão sobre o cuidado, a ocupação e a preocupação.
} 
Heidegger compreende a figura do humano como um ente cujo ser consiste num poder-ser, sendo esta característica sua determinação mais original, podendo cada ser-aí ser possível de ser. É na existência que o ser-aí lançado no mundo se constitui. No mundo, o ser-aí conjuga seu próprio ser, então compreende sua situação como a de um "ser-em-um-mundo"; tendo, assim, uma relação de familiaridade com o mundo e os entes que vem ao seu encontro. O ser-aí em contato com esses entes que vem do mundo acaba por se relacionar com eles, gerando assim um modo prático de lida, fazendo com que esses entes estejam sobre uma relação de ocupação (KAHLMEYER-MERTENS, 2015, p. 80).

Lançando bases sobre o conceito de ocupação (Besorge), Heidegger compreende esta como sendo a atividade do ser-no-mundo por meio da qual este lida com seus afazeres e se faz em sua existência mais imediata, cotidiana. Nesse sentido, a existência, enquanto dinâmica de ser do ser-no-mundo, se perfaz por meio dos modos de ocupação ou, como o próprio Heidegger afirma: "[...] o seu ser para com o mundo é, essencialmente, ocupação" (HEIDEGGER, 2011, p. 103). A ocupação, desse modo, caracteriza propriamente o seu modo de ser no espaço constitutivo em que ocorre a realização do ente, ou seja, nos seus modos de ocupação. A forma em que o ser-no-mundo existe em contato com os entes no mundo define-se como os seus modos de ocupação, seja por meio de um fazer e/ou empreender ou até mesmo de uma desocupação, isso ocorre através da busca de realizar os seus projetos existenciais vindo a ser o ente que é na medida de suas potencialidades. Nesse contexto, a ocupação adquire três significados: 1) obter algo, adquirir para si, prover-se; 2) tratar de..., cuidar de...; e 3) estar ansioso por..., perturbado por ou preocupado com algo. (HEIDEGGER, 2011). Esses desdobramentos do significado de ocupação são complementares entre si, e acabam por tornarem-se constituintes do cotidiano do ser-no-mundo em sua relação com os outros demais seres-no-mundo (KAHLMEYER-MERTENS, 2015, p. 87).

Similarmente à ocupação, também a preocupação (Fürsorge) é um modo de ocupação. Esta ocorre quando o ser-no-mundo se preocupa com outro ser-nomundo que pode se mostrar ligado a ele em uma relação de convívio, ou melhor, de co-existência (Mit-Sein). A preocupação é um modo de lidar com o outro, mas não menos pessoal que a ocupação, sendo que ambos estão relacionados às ocupações do mundo cotidiano. É em face disso que Heidegger nos assegura de que a essência do ser-no-mundo: “[...] pode-se compreender, [...] o ser junto ao manual como ocupação e o ser como coexistência dos outros nos encontros dentro do mundo como preocupação" (HEIDEGGER, 2011, p. 260). Por esse motivo, a preocupação é o modo de lida cotidiana, um modo de ser-com, os demais seres-aí, pois há o envolvimento existencial de um ser com os outros, juntos aos demais entes intramundanos.

Por fim, temos o cuidado (Sorge). A este existencial, Heidegger confere 
importância especial, ele seria a estrutura existencial que é base para a ocupação e preocupação, no entanto, não se confunde com elas, já que, afinal, elas são derivadas do mesmo. O cuidado, assim, liga-se a questões puramente ontológico-existenciais, estando, portanto, relacionado ao modo básico de ser do ser-aí. Ele próprio possui uma dinâmica que exclui toda a sua tendência ôntica de apropriação, e acaba por estar ligada às dimensões dos afazeres do cotidiano, no qual acabamos por nos ocupar com algo, seja referente a questões em que tratamos de um assunto coletivo ou referente a questões particulares. Este conceito apresenta o comportamento do ser-aí na sua tarefa de estar na dinâmica de ser e de continuar sendo. O ser-aí se apresenta como inacabado, pois a cada instante necessita apropriar-se de si próprio, e pelo cuidado o ser-no-mundo apresenta-se como existindo, gerando assim o movimento em que sempre há à necessidade do ser-aí apropriar-se de si mesmo, e o cuidado como sendo fonte da apropriação do seu ser.

\section{Solicitude enquanto preocupação segundo uma interpretação fenomenológica de La Salle}

A preocupação em Heidegger seria uma das formas de ocupação do ser-nomundo, assim como cuidado, mas a preocupação e a ocupação também assumem a forma de cuidado. No convívio entre os indivíduos, na relação entre um ser-nomundo com outro ser-no-mundo é que se gera a preocupação, pois liga-se ao envolvimento existencial entre os seres. "Para Heidegger, gestos que expressam zelo, assistência, tutela ou responsabilidade por alguém (inclusive os que envolvem o tratamento de um enfermo ou a prática educativa) seriam preocupação em vista de uma relação de ser com o outro" (KAHLMEYER-MERTENS, 20o8, p. 29). Esse modo de ocupação, que possui como base o envolvimento entre um ser-no-mundo com outro ser-no-mundo, denominado preocupação ganha proximidade com o conceito de solicitude, pois a forma de ocupação possui correlação entre os indivíduos pelo seu modo de preocupação.

Essa forma estabelecida por Heidegger, como forma de ocupação, cuidado e preocupação, é percebida em La Salle através da prática educativa como uma forma de ocupação e cuidado que visa a preocupação do educador para com o educando. Se em Heidegger percebe-se a preocupação na relação entre o ser-no-mundo com outro ser-no-mundo, em La Salle essa relação possui seu foco no ato de educar.

La Salle não mascara seu ponto de vista: as crianças não são alunos, mas "discípulos"; o professor não é funcionário, mas substituto dos progenitores, representantes de Jesus Cristo, "ministros" de Deus e da Igreja. A criação não está acabada: o educador participa no progresso de cada aluno em vista da melhoria da sociedade para a felicidade temporal e eterna de cada qual (POUTET; PONGIER, 2001, p. 114).

A relação que La Salle propõe entre as crianças que eram educadas em suas 
escolas e o papel do professor é de coexistência. Os alunos não estão frequentando a sala de aula para aprender somente o conteúdo, mas que o processo de ensino ultrapasse as questões conteudistas e venha agregar elementos em sua existência, por esse motivo, La Salle não chama as crianças de alunos, mas sim discípulos. Esse processo realizado pelo estudante só é possível se o professor comprometer em assumir seu papel de condutor da sua existência e de seus alunos. Para isso, La Salle chama os educadores não semente a transmitir o que é correto, mas para exerce de forma prática em suas vidas todos os elementos que ensinam e transmitem as crianças: “[...] é fácil concluir que muito imperfeito seria o vosso zelo com as crianças que dirigis, se apenas o exercêsseis pelo ensino, mas que se tornará perfeito, se vós mesmos praticais o que lhes ensinais" (LA SALLE, 2012, p. 464b).

É nesse comprometimento do educador que se caracteriza a preocupação, pois ele está comprometido em exercer de forma plena em sua vida aquilo que ensina. Nessa ação de educar as crianças com tamanha preocupação é que se caracteriza o conceito de solicitude em La Salle. É nessa relação que se gera o processo pedagógico, naquilo que o educador ensino e mostra de exemplo da sua própria vida. É na prática cotidiana de sua existência que possui proximidade com a existência de seus alunos, naquilo que Heidegger chama de co-existência (Mit-sein), que o educador está preocupado com aquilo que transmite a seus educandos. A solicitude não está dissociada da preocupação, muito menos de uma forma de ocupação, pois em La Salle ela é entendida como um modo de ocupar-se e de comportar-se preocupado com o outro. É um modo de existir, no caso do educador, de servir de exemplo prático através da sua própria existência, na qual a existência do outro está presente.

\section{Considerações finais}

Diante do exposto ao longo deste artigo, percebe-se que o conceito de solicitude em La Salle caracteriza-se como sendo a própria conduta gerida pelo educador mediante seus educandos. Essa conduta é mediada pela preocupação que o professor possui com o ensino ministrado a seus alunos, sendo não somente o ensino formal e conteudista, mas o próprio exemplo das suas ações existenciais.

A solicitude possuindo uma mediação pelo conceito de preocupação em La Salle, ganha proximidade com a filosofia existência de Heidegger. A preocupação em Heidegger assume um modo de ocupação do ser-no-mundo que se ocupa com outro ser-no-mundo, é uma forma de lidar preocupado de um ser-com outro ser-aí. Nessa relação de preocupação existencial do educador para com os seus educandos, que surge um modo pedagógico guiada pelo viés da solicitude. O educador é responsável em guiar pedagogicamente e existencialmente seus alunos, tanto pela sua forma de educá-los, quanto pelo exemplo que os dá através sua existência. 


\section{Referências}

HEIDEGGER, M. Ser e tempo. Trad. Marcia Sá Cavalcante Shuback. Petrópolis, RJ: Editora Universitária São Francisco, 2011.

JUSTO, H. La Salle: patrono do magistério: vida, bibliografia, pensamento, obra pedagógica. Porto Alegre: Santo Antônio, 1991.

KAHLMEYER-MERTENS, R. S. 10 lições sobre Heidegger. Petrópolis, RJ: Vozes, 2015. . Heidegger E a educação. Belo Horizonte: Autêntica, 2008.

LA SALLE, J. B. Guia das escolas cristãs. Trad. Albino Afonso Ludwig e Albano Constâncio. Canoas, RS: Editora Unilasalle, 2012.

. Obras completas de São João Batista de La Salle. Coord. Edgar Hengemüle. Trad. Albino Afonso Ludwig... [et al]... Canoas, RS: Unilasalle, 2012.

POUTET, Y; PUNGIER, J. La Salle e os desafios de seu tempo. Trad. Henrique Justo. Canoas, RS: La Salle, 2001.

Submissão: 10.11.2018 / Aceite: 30.11.2018 